\section{Popper, Wolpert and critics}

SIR - Lewis Wolpert (Nature 360, 204; 1992) seems so profoundly to misunderstand Popper's philosophy that I can only conclude he has never ready any.

Popper does not maintain, as Wolpert claims, that ". . . only falsification is important. .." in the procession of science. Popper proposed that falsifiability is the criterion for the demarcation between science and nonscience. However, a nonscientific or metaphysical theory can prove very influential in the procession of science, for example Popper's theory of falsifiability. The fact that Popper's theory is metaphysical seems to be the root of Wolpert's misunderstanding. A metaphysical theory can, it is true, be meaningful and useful, but if there is no means of testing its truth there can be no empirical support for that truth: that is why it is nonscientific or metaphysical by Popper's criterion. Hence, when Wolpert asks of Popper's theory, "How would one falsify it?", he does not, as one assumes he intends, point out that Popper's theory is nonsense, but demonstrates his own misunderstanding. Wolpert seems to hold the misconception of falsifiability not as the demarcation between science and nonscience but between sense and nonsense. Thus, Wolpert suggests that the nonsense statement, ". . . eating hamburgers will make you a good poet", is falsifiable, but it is not. I would like to know Wolpert's indisputable criteria for distinguishing between a good poet and a bad poet.

Worse still, Wolpert does not appear to understand the problem of induction that Popper tried to solve. Wolpert says, "the theory [Popper's] does not even resolve the problem of induction, for one wants to have a sufficient number of experimental falsifications to be persuaded". The number of "experimental falsifications" that Wolpert considers "sufficient" for him to be "persuaded" is a matter for his own personal psychology and has no logical bearing on the validity of Popper's theory. This is the very problem Hume identified with inductive reasoning and Wolpert has presented a fine example with his silly argument.

\section{S. C. Francls}

Institute of Zoology,

Zoological Society of London.

Regent's Park, London NW1 4RY, UK

SIR - When judging the success of Karl Popper, we should perhaps view him as a moralist who prescribes the proper, most productive behaviour of scientists, the path he would have us follow. The philosophers following Kuhn are then viewed as historians, who report how people called scientists actually behave; and Popper's success is best measured by the number of scientists he has led down his path.

Robert Eisenberg

Department of Physiology,

Rush-Presbyterian-St Luke's

Medical Center,

Chicago, IIIinois 60612, USA

SIR - John Polkinghorne (Nature 360, 378 ; 1992) berates Lewis Wolpert for remarking, in The Unnatural Nature of Science, that "[s]cientific knowledge. . provides our best way of understanding the world". From the context it is clear that Wolpert means a rigorous understanding. Other disciplines such as history or philosophy provide some understanding, but at a different level of precision. Polkinghorne writes that "a painting is more than a collection of specks of paint", implying that science cannot account for the impact of a great painting on the viewer. Nor can it, nor has anybody claimed that it can: perhaps it never will, we cannot know.

Polkinghorne goes on to attack Wolpert for not paying attention "to the source of our intuition of the value of human individuals". Some of us have that intuition, some of us do not. But intuition is extremely fallible and whenever it has been compared with a more scientific approach it has been shown to be less successful, as for example in medical diagnosis. Scientists have intuitions about science, others have intuitions about the existence of God, and Hitler had the intuition that the Aryan race was so superior to others that they should be destroyed.

As Wolpert makes abundantly clear, the difference between scientific intuition and other kinds is that only the former can be tested. The question Polkinghorne poses - how morality originates - is not, as he suggests, necessarily unanswerable by scientists: sociobiologists have already taken a rather crude crack at it. The more important question, which Polkinghorne neither raises nor answers, is how specific ethical or religious beliefs can be defended. In the last analysis they cannot, except by announcing, "I feel it: I have faith." Pace Polkinghorne, Wolpert is surely right in claiming that science is incompatible with religion. Perhaps Polkinghorne should ponder the dilemma that would arise if science were ever able to explain the origins of religious and ethical beliefs: the distinction between explaining and explaining away is a fine one.

\section{Stuart Sutherland}

Laboratory of Experimental Psychology,

University of Sussex,

Falmer, Brighton BN1 9QG, UK
Research benefits

SIR - - Your attempt to correct President George Bush's attempt to cite unexpected benefits of basic research as justification for its funding (Nature 358, 530; 1992 ) is flawed, albeit to a lesser degree than his.

At the time under discussion, I was head of research and development at Cobe Laboratories of Lakewood, Colorado, and also a member of the board of directors of Galen Laboratories. To say that "Cobe modified his invention so that it could be manufactured" is to misunderstand the essence of product development. An "invention", purporting to be a product, that cannot be manufactured is a contradiction in terms. To be an invention, by definition it must be useful. My colleagues and I developed a superb manufacturing process and associated product design (more often than not the two are symbiotic) which continues to this day (some 18 years later) producing high quality medical devices. In so doing we were awarded patents exceeding in number those awarded to Mr Finley Markley.

Our dialyser was initially marketed at $\$ 27.50$; later pricing (actual high volume sales, not list) was in the $\$ 16$ range. The Cobe technology was not sold to a Yugoslav company. Your statement to the contrary notwithstanding, it is not difficult to measure the impact of Markley's work on those with chronic kidney disease. There were at the time of the introduction of the Medical Inc. dialyser a number of acceptable artificial kidneys. Had Markley's invention not occurred, these other products would have readily supported the patient requirements. Even though the same is true of the Cobe dialyser, my colleagues and I remain proud of the number of patients who received safe and effective treatment from our product.

Your article ignores or even minimizes a far more critical issue. What in the world was the 'management' of Argonne Laboratories thinking of when it allowed tax dollars to be frittered away on a matter that did not relate to its missions and regarding which its organization had no expertise? In short, even if Bush's story had been true, it would not have been cause for celebration but should have raised these questions.

It is the repetition of this story - the arrogant ignoring of the funded mission with the concomitant diversion of funds from the mission to "targets of opportunity" - that is causing the loss of support for the national laboratories on the part of both legislators and taxpayers.

Donn D. Lobdell

1524 Sandcastle,

Corona Del Mar, California 92625, USA 